\title{
Ludzie i przedmioty Literatura dla dzieci jako szkoła estetycznej wrażliwości
}

\begin{abstract}
People and objects
Children's literature as an aesthetic school of sensitivity

Abstract: The focus of research in the field of literature for children and youth on objects results from post-humanistic methodologies and brings about interesting results. Objects play different roles in children's texts, just as they play different roles in the works of artists, for instance Tadeusz Kantor and Joanna Rajkowska. By interpreting literary texts and works of art, I try to show that the representations of objects from both areas are similar and can serve to the aim of children's aesthetic education.
\end{abstract}

Key word s: posthuman studies, children's literature, aesthetic education, avant-garde art

Nowa humanistyka jako kierunek badań humanistycznych tworzy własne projekty badawcze, odznaczające się troską o wartości oraz idee oparte na poszerzeniu obszaru antropologicznego w kontekście doświadczenia. Polegają one na odrzuceniu stricte biologicznego pojęcia natury ludzkiej, a wpisaniu i rozpatrywaniu jej w ramach specyficznych znaczeń „kulturonatury”, a więc historii i przyrody, tego, co społeczne, i tego, co biologiczne. W wyniku takiej procedury powstają nowe kierunki badań, jak choćby studia nad materialnością (rzecza$\mathrm{mi}$ ), studia afektywne czy animal studies, water studies, badania nad roślinnością, ekokrytyka czy teoria aktora-sieci.

Szczególnie interesują mnie reprezentacje rzeczy, przedmiotów, które w literaturze dziecięcej często odgrywają istotną rolę. Są to zabawki, fragmenty garderoby, przedmioty ceremonialne, naczynia kuchenne, urządzenia techniczne czy motywy roślinne zdobiące przedmioty codziennego użytku. Niektóre z nich są wykorzystywane do dziecięcych zabaw, a inne stają się inspiracją działań artystycznych. Spośród utworów, w których przedmiot odgrywa takie właśnie role, warto wymienić choćby: Bezsenność Jutki Doroty Combrzyńskiej-Nogali, 
Czy umiesz gwizdać, Joanno? Ulfa Starka i Anny Höglund, Listy w butelce. Opowieść o Irenie Sendlerowej Anny Czerwińskiej-Rydel, Aksamitnego królika Margery Williams, Królewnę Roksany Jędrzejewskiej-Wróbel, Od rzeczy do rzeczy Wandy Chotomskiej, Dziwne przypadki bajkopisarza Grzegorza Kasdepkego, Trochębajki o Stanisławie Wyspiańskim Katarzyny Maziarz. Występujące w tych utworach rzeczy często stają się bohaterami akcji, a prezentując się w nieoczekiwanych okolicznościach, tworzą mocne relacje z ludźmi. Oto kilka przykładów:

Skakanka wydobyta ze starego pudła, która sprawiała dzieciom radość, nawet tym, które znalazły się w getcie. Okazała się nie tylko zabawką — skakanką, ale przede wszystkim „pocieszanką", oswajającą choć na chwilę potworny lęk osób zamkniętych w getcie. Bo kiedy Jutka słyszała rytmiczny odgłos skoków dzieci bawiących się skakanką, czuła się tak, jakby unosiła się w górę.

Combrzyńska-Nogala, 2014

Latawiec z ogonem, którego funkcję spełniał krawat „adaptowanego dziadka”. Scena ta, mimo że jest hołdem składanym zmarłemu dziadkowi, to jednocześnie ma ludyczny wymiar, wszak unoszenie się latawca wzbudza w bohaterach pozytywne emocje.

Stark, Höglund, 2008

Butelka po mleku ukrywająca skarb. Wypełniona bibułkami z nazwiskami dzieci wyprowadzonych z getta przez Sendlerową, została zakopana pod drzewem - jabłonką, można powiedzieć pod „drzewem życia”.

Czerwińska-Rydel, 2018

Królik wypchany trocinami, ale ożywiony. W doświadczeniu dziecka był miękką ciepłą, pachnącą, a więc ulubioną zabawką przytulanką. Potem wyrzucony do kosza przez rodziców bojących się zarazków szkarlatyny stał się śmieciem - przedmiotem brudnym, lepkim, brzydko pachnącym. Dopiero wróżka, która przybyła z magicznej Krainy Dziecięcego Pokoju, darowała mu prawdziwe życie. Stał się żywy jak jego właściciel — paroletni chłopczyk.

Williams, 2009

Piękna i błyszcząca korona, która jednocześnie dodawała blasku bladej i chudej królewnie, ale jednocześnie oddalała ją od bawiących się na podwórku dzieci. Dzieci zdziwione obecnością królewny nie były pewne, czy można z nią zagrać zniszczoną piłką albo poskakać przez gumę pełną supłów.

Jędrzejewska-Wróbel, 2004, s. ??

Dziwny kran w łazience z kolorową wodą wywołuje zachwyt dzieci, ale nie dlatego, że można pod nim umyć ręce. Powodem zachwytu są wrażenia, jakie wywołuje imaginacja: szum, kolor, nieuchwytność wody i jej „mokrość” są dla dzieci niezwykle atrakcyjne.

Chotomska, 2012

Aparat fotograficzny, który czynił cuda. Pozwalał dziecku uchwycić właściwy moment codziennej sceny, która w jego obiektywie stawała się jednak czymś 
niecodziennym (zdjęcie wody cieknącej z rynny nosiło podpis: Wodospady Iguany, a fotografia żuków na ścieżce - Dinozaury).

Kasdepke, 2010

Roślinny motyw na witrażu, zainspirowany chwastem - dziewanną. To dzięki jego obecności autorka książki o Stanisławie Wyspiańskim mogła napisać: „Mury kościoła zakwitły niczym ogromna łąka”...

Maziarz, 2018, s. 91

Dzieci są mocniej związane z przedmiotami niż dorośli. Nie przyjmują do wiadomości ich statusu jako przedmiotów martwych, bo wierzą w ich żywotne podobieństwo do siebie. Może właśnie dlatego dzieci często śnią na jawie o żywym kontakcie z zabawkami, marzą o tym, aby latać (nie martwią się, że udaje im się to zrealizować tylko częściowo w zabawie skakanką), czują się dobrze w świecie kolorów i kształtów, realizują swoje podróżnicze „zachcianki” dzięki aparatowi fotograficznemu oraz własnej inwencji twórczej.

Wydaje mi się, że to właśnie pod wpływem tych pragnień i afektywnych pobudzeń powstają $\mathrm{w}$ ramach twórczości literackiej dla dzieci niezwykłe teksty, które są plątaniną głosów, obrazów, afektów, doświadczeń zmysłowych (Mik, Niewieczerzał, Rąbkowska, Leszczyński, red., 2019). Dzieciom to nie przeszkadza, ponieważ potrafią $\mathrm{w}$ kontakcie $\mathrm{z}$ utworem literackim wejść $\mathrm{w}$ środek świata przedstawionego i przeorganizować go według własnych pragnień, które są z kolei bogatym źródłem obrazów literackich. Przykładem tego rodzaju zachowań dzieci jest scena z Bezsenności Jutki, kiedy dziadek opowiada wnuczce mityczną baśń o Dedalu i Ikarze, która ma w jakiś sposób dać nadzieję na uwolnienie z łódzkiego getta:

Ikar tak się zachwycił lotem, że zapomniał o przestrogach ojca i poleciał wysoko, bardzo wysoko i... słońce roztopiło wosk i spadł.

— Zbudujesz dla nas takie skrzydła? - ożywiła się wnuczka.

— To baśń. Musimy wymyśleć coś innego, jakiś inny rodzaj skrzydeł, inną ucieczkę.

- Szkoda. Ja bym ciebie słuchała i Estera, i Josek, i Jana, i Chaja, a nawet ryży Czesiek by ciebie słuchał, żeby tylko polecieć. Lecielibyśmy sobie razem z Wawelskim na wolność, może nawet do Zgierza.

Jutka usnęła, marząc o wspaniałym locie.

Combrzyńska-Nogala, 2014, s. 43-44

Wymarzone i oczekiwane przez Jutkę skrzydła musiała jednak zastąpić skakanka. Można przyjąć, że Jutka, myśląc o tym przedmiocie i używając go, sprawia, że skakanka pozwala jej na „odmienne stany świadomości”, pozwala stać się jej kimś innym. Marek Krajewski stawia interesującą tezę, że zdarzają się i takie sytuacje, w których to przedmioty pozwalają ich użytkownikom stawać się ludźmi (Krajewski, 2013). Jakie ma to konsekwencje dla opowieści o dziewczynce uwięzionej w łódzkim getcie? Myślę, że dzięki skakance rodzi się wspólno- 
ta zabawy. Ten przedmiot choć na chwilę przywraca nie tylko utracone dzieciństwo, ale również niemalże plemienne myślenie człowieka (Waksmund, 2000, s. 42). W innym tekście zatytułowanym Królewna Jędrzejewskiej-Wróbel korona odłożona na bok pozwala bohaterce („królewnie”) stać się po prostu dziewczynką z podwórka, nie przeszkadzając wisieć jej na trzepaku głową na dół. Innymi słowy, korona podobnie jak skakanka przywraca jedność w plemieniu dzieci.

Dzieci zainspirowane utworami literackimi włączają je często w praktyki zabawowe (wizualne, dźwiękowe, działaniowe - Baluch, 1979). W ich ramach pojawiają się pytania oraz zadania: „Narysuj”, „Zaśpiewaj”, „Pokaż to, co przygotowałeś”. Zadania często sprawiają, że realizujący i występujący przed publicznością jest zarówno twórcą, jak i materią sztuki. Tym samym w zabawie wartość przedmiotu nie ujawnia się autonomicznie. To na skutek pewnych działań zabawowo-artystycznych przedmiot zyskuje lub zwiększa swoją wartość (Ingarden, 1966, s. 100, 300 i nast.). Nasuwają się więc pytania dotyczące znaczenia lub wartości przedmiotu, a także tego, jak rzeczy pozostające w splocie z człowiekiem powinny być analizowane. Inne interesujące pytania to: Dlaczego rzeczy mniej aktywne i słabsze są pełnoprawnymi współtwórcami rzeczywistości? Jak można dać rzeczom „biednym” nowe życie?

Nie sposób choćby w części odpowiedzieć na te pytania bez badania splotów, w jakie uwikłani są człowiek i przedmioty. Przykładem takiego układu jest kolejna scena z Bezsenności Jutki. Skakanka wyjęta ze starego pudła (prawdopodobnie poplątana i brudna) przydaje się Jutce, słabiutkiej Chai i Janie, przerażonym dziewczynkom, zamkniętym w getcie. Pomimo tak dramatycznej sytuacji łączy je zabawa w grupie, dając im poczucie więzi (można też uznać, że wiąże je sznurek). Skakanka przywraca im na chwilę poczucie bezpiecznego i radosnego dzieciństwa, choć osłabienie jednej z dziewczynek spowodowane głodem wywołuje smutek jej koleżanek. Warto zauważyć, że niebagatelną rolę w zabawie odgrywa słowo. Pojawiają się więc wyliczanki w języku polskim i jidysz. Rytm tych wierszy, czasem ich absurdalność podtrzymują dobry nastrój i zbliżają dzieci. W opisanej sytuacji między nimi a przedmiotami nie ma podziału. Skakanka „skacze” tak, jak jej użytkowniczki: raz lepiej, raz gorzej. Jest wspólną własnością dziewczynek, więc to one decydują o jej przydatności, a ona - o ich nastroju. Przedmioty i ludzie wzajemnie się wspierają. Wszystkie elementy: dzieci, sznurek, emocje, zamknięta przestrzeń, stukot bucików oraz rytm wyliczanek tworzą sieć getta, w którym przebywają dzieci, naprzemiennie się bojąc, chowając, bawiąc, słabnąc z głodu, bawiąc...

Wydaje się, że zasadne jest porównanie awangardowej sztuki XX wieku do współczesnych utworów literatury dziecięcej, w których znajdują swe reprezentacje przedmioty biedne, słabe, tak bardzo dzięki temu tożsame z ludźmi (poszarpana i brudna skakanka wyjęta ze starego pudła, pomięty i poplamiony krawat, lepka butelka po mleku, piękna i błyszcząca korona, oblepiony brudem aksamitny królik, kolorowa woda $\mathrm{z}$ kranu, popsuty, a może zaczarowany aparat foto- 
graficzny, obraz chwastu na kościelnym witrażu). Te brzydkie, poniszczone rzeczy sygnalizują najmłodszym istnienie „prawdziwego”, a nie wyidealizowanego świata przeciwstawionego temu czystemu i poprawnemu. W prawdziwym świecie rzeczy się psują lub są psute, a ludzie chorują, są coraz słabsi, starzeją się. To, co istotne, to przesłanie takiego zestawienia ludzi i przedmiotów: wszyscy potrzebują dobrego traktowania. Sztuka może o tym przypominać, wszak potrafi ukazać związki ludzi z przedmiotami, które niejako „definiują” człowieka.

Doświadczenie zamierzonego chaosu, braku przyległości, niespodziewanych, a więc raczej niemimetycznych układów, jakie może wywołać w dziecku kontakt $\mathrm{z}$ adresowaną do niego literaturą podejmującą zagadnienia związków ludzi i przedmiotów, może potem być powtórzone w dorosłości podczas zetknięcia się z awangardową sztuką XX i XXI wieku, np. z dziełami Tadeusza Kantora czy Joanny Rajkowskiej.

Jak wiadomo, artystą, który wyraźnie wiązał rzeczy z ludźmi, nadając w swym teatrze jednym i drugim metafizyczną rangę, był Tadeusz Kantor. Świadomie wybierał przedmioty wzięte $z$ życia, najprostsze, prymitywne, stare, $z$ wyraźnymi śladami zużycia, bo, jak twierdził, tylko takie „najbiedniejsze przedmioty”, rzeczy „inne”, mniej aktywne oraz słabe, ale związane z człowiekiem na zasadach tożsamości, mogą stawać się prawdziwymi dziełami sztuki, w których kumulują się nowe znaczenia i uwyraźnia się ich symbolika. Ponieważ poniszczone rzeczy z łatwością wyrzuca się do kosza, Kantor chciał je wyzwolić spod hegemonii człowieka, aby je odzyskać i ocalić. Realizował tym samym ideę troski o rzeczy, praktykując ją w swym teatrze śmierci, należącym do ostatniego etapu w twórczości teatralnej Kantora. W jego spektaklach: Umarła klasa, Wielopole, Wielopole, Niech sczezna artyści, Nigdy już tu nie powróce, Dziś sa moje urodziny tematyka śmierci była wszechobecna, ale w specyficzny sposób, np. jako nakładające się na siebie obrazy z życia rodziny, wspomnienia wojenne i sceny nawiązujące do męki Chrystusa. W sztuce Wielopole, Wielopole pomiędzy zwyczajne meble, jak łóżko czy szafa, wdzierają się krzyże, wdzierają się rekruci prosto $\mathrm{z}$ pierwszej wojny światowej... Zestawienie tych przedmiotów coś znaczy. Mieszają się w nich wspomnienia z dzieciństwa, obrazy przeszłości, sceny umierania i pogrzebu... Tak tłumaczy te związki ich twórca ${ }^{1}$. Ale być może ukazują one co innego: esencję życia, czyli po prostu plątaninę osób, zdarzeń, słów i snów... Ten swoisty nieporządek kończy śmierć, która jest wyzwoleniem z chaosu, ponieważ zapewnia harmonię oraz wolność.

Dla Kantora najważniejszą sprawą egzystencjalną, uwidocznioną w jego teatrze była wolność. Widać to w jego twórczości oraz wypowiedziach na temat sztuki: „Ogarnia mnie ciągłe pragnienie, czy marzenie i wołanie, by twórczość była wolna, podległa tylko mnie, moim słabościom, szaleństwom, chorobom,

1 Teatr śmierci Tadeusza Kantora. Wielopole, Wielopole. https://culture.pl/pl/artykul/teatr-smier ci-kantora-w-pieciu-odslonach [data dostępu: 10.02.2020]. 
moim klęskom, mojej samotności...” (Miklaszewski, 1992). Pisał także: „Dzieci wszystkich krajów na całej ziemi jednakowo malują: ta sama wyobraźnia, ta sama ekspresja, ta sama wolność" (Miklaszewski, 1992). To poczucie wolności w sztuce słowa pozwala artystom i dzieciom na porozumienie, które wyraża kolejne zdanie Kantora: „Rytm twórczości jest nieprzerwany; wymaga totalnego, bez reszty permanentnego zaangażowania myśli, woli i wyobraźni”"2.

Współczesna literatura dziecięca ma dużo wspólnego z Kantorowską koncepcją świata. Bo czyż jego Pokoik Wyobraźni ze sztuki Wielopole, Wielopole nie pełni podobnej magicznej albo metafizycznej funkcji, jak Magiczny Dziecięcy Pokoik z Aksamitnego królika? W obu przestrzeniach dzieją się rzeczy niezwykłe. Plączą się przedmioty, gubi się czas, mieszają się poziomy akcji, obecność metafizyki jest namacalna. Aksamitny królik wraca z zaświatów, ponieważ do magicznego Dziecięcego Pokoiku przychodzi wróżka, która sprawia, że trocinowe zwierzątko staje się Prawdziwe.

Joanna Rajkowska jest współczesną artystką, tworzącą instalacje w przestrzeni publicznej. Jest m.in. autorką projektu Pozdrowienia z Alej Jerozolimskich, którego główny element stanowi sztuczna palma na rondzie Charles'a de Gaulle'a w Warszawie. Rajkowska tropi niejednoznaczne sytuacje i projektuje przestrzenie tak, jak Kantor - po swojemu. Jej projekt, choć odnosi się do konkretnej współczesnej i pożydowskiej przestrzeni, pozostaje bliski również poetyce snów i marzeń (sztuczna palma jest wszak elementem surrealistycznym). W tym sensie kontakt ze sztuką współczesną wymaga nie tylko racjonalnego, ale przede wszystkim wrażeniowego i afektywnego odbioru, będącego podstawą opisu, analizy i interpretacji oraz wartościowania dzieła. Taki właśnie emocjonalny odbiór, ale bez procederów badawczych jest typowy dla dzieci. To one żyją w świecie emocji i reagują spontanicznie. To dla nich materia jest podstawą twórczości: kreują własny świat z papieru, ze sznurka, ze szkła, z aksamitu, kwiatów, a także z własnego ciała. Mali czytelnicy książki Czy umiesz gwizdać, Joanno? w sposób naturalny akceptują to, że chłopiec na pogrzebie dziadka gwiżdże mu piosenkę, inicjując w ten sposób piękną, wzruszającą, a przede wszystkim niebanalną scenę pożegnania. Widać, że autorzy omawianych książek dla dzieci nie korzystają w pełni z klasycznych reguł i konwencji budowania zdarzeń oraz postaci, a ich dzieła to próby otwartych eksperymentów, jak w twórczości Rajkowskiej. Jak sama artystka twierdzi, posiłkuje się w działaniach artystycznych „zwierzęcym instynktem", dlatego istotne jest dla niej to, co nieracjonalne, afektywne, emocjonalne. Artystka mówi, że czuje się „szamanką"” i podczas tworzenia wchodzi w pewnego rodzaju trans.

Uważam, że taki stan może być wywołany kontaktem ze sztuką, z pasjonującą lekturą, która najmłodszym dzieciom pozwala nie tylko działać na sa-

\footnotetext{
${ }^{2}$ https://zyciorysy.info/tadeusz-kantor/ [data dostępu: 10.02.2020].

3 https://culture.pl/pl/tworca/joanna-rajkowska [data dostępu: 10.02.2020].
} 
mej materii książki - obgryzać, drzeć kartki, kolorować lub dorysowywać obrazki, ale również słuchać czytanego tekstu lub samemu próbować składać literki. Dobrze dobrany utwór pozwala twórcy i odbiorcy przemierzać różne światy, wszak szaman potrafi odprowadzać umarłych w zaświaty (Sendlerowa wyprowadza dzieci z getta, latawiec odprowadza Dziadka na „drugą stronę”). Szamani, a także artyści, a więc i dzieci, uznają świat ożywiony, ale co najważniejsze, również przedmioty „bramy”, dzięki którym można wejść w relacje oraz reagować we wspólnym działaniu. Szamani, czyli także autorzy opowieści (Dorota Combrzyńska-Nogala, Ulf Stark i Anna Höglund, Anna Czerwińska-Rydel, Margery Williams, Grzegorz Kasdepke, Katarzyna Maziarz), mają odpowiednie zdolności, aby leczyć opowieściami, które znajdują się w książeczkach dla dzieci - „cudownych i pożytecznych” przedmiotach.

\section{Literatura}

Baluch A., 1979, Poezja wspótczesna w szkole podstawowej, Warszawa.

Chotomska W., 2012, Od rzeczy do rzeczy, Kozieł-Nowak M., ilustr., Łódź.

Combrzyńska-Nogala D., 2014, Bezsenność Jutki, Rusinek J., ilustr., Łódź.

Czerwińska-Rydel A., 2018, Listy w butelce. Opowieść o Irenie Sendlerowej, Szymanowicz M., ilustr., Łódź.

Ingarden R., 1966, Przeżycie, dzieło, wartość, Kraków.

Jędrzejewska-Wróbel R., 2004, Królewna, Oklejak M., ilustr., Warszawa.

Kasdepke G., 2010, Dziwne przypadki bajkopisarza, Kozieł-Nowak M., ilustr., Łódź.

Krajewski M., 2013, Sa w życiu rzeczy... Szkice z socjologii przedmiotów, Warszawa.

Maziarz K., 2018, Trochębajki o Stanisławie Wyspiańskim, Zając M., ilustr., Kraków.

Mik A., Niewieczerzał M., Rąbkowska E., Leszczyński G., red., 2019, O czym mówia rzeczy? Świat przedmiotów w literaturze dziecięcej i młodzieżowej, Warszawa.

Miklaszewski K., 1992, Spotkania z Tadeuszem Kantorem, Kraków.

Stark U., 2008, Czy umiesz gwizdać, Joanno?, Höglund A., ilustr., Skalska K., przeł., Poznań.

Waksmund R., 2000, Od literatury dla dzieci do literatury dziecięcej (tematy - gatun$k i-k o n t e k s t y)$, Wrocław.

Williams M., 2009, Aksamitny królik, Nicholson W., ilustr., Grabowska B., przeł., Warszawa.

\section{Źródła internetowe}

https://culture.pl/pl/tworca/joanna-rajkowska [data dostępu: 10.02.2020].

https://zyciorysy.info/tadeusz-kantor/ [data dostępu: 10.02.2020].

Teatr śmierci Tadeusza Kantora Wielopole, Wielopole. https://culture.pl/pl/artykul/teatrsmierci-kantora-w-pieciu-odslonach [data dostępu: 10.02.2020]. 
Alicja Baluch - profesor doktor habilitowana, literaturoznawca, profesor zwyczajny Uniwersytetu Pedagogicznego w Krakowie, wieloletni kierownik Katedry Literatury dla Dzieci i Młodzieży oraz Katedry Literatury XX Wieku. Jej dorobek naukowy koncentruje się wokół teorii literatury, pogranicza sztuk (literatury i malarstwa) oraz zagadnień dotyczących zastosowania kontekstów mitograficznych do interpretacji polskiej i światowej klasyki literatury dziecięcej. Opublikowała wiele książek naukowych, m.in. Archetypy literatury dziecięcej (1987), Ceremonie literackie, a więc obrazy, zabawy i wzorce w utworach dla dzieci (1996) wyróżnione przez IBBY Nagrodą Roku, Uważne czytanie. $W$ kręgu liryki XX wieku (2000), Książka jest światem. O literaturze dla dzieci małych oraz dla dzieci starszych i nastolatków (2005), Od form prostych do arcydzieła. Wykłady, prezentacje, notatki, przemyślenia o literaturze dla dzieci i młodzieży (2008). W Bibliotece Narodowej ukazał się w jej opracowaniu tom Tytus Czyżewski. Poezje i próby dramatyczne (1992). Jest członkiem Oddziału Krakowskiego Stowarzyszenia Pisarzy Polskich. Wydała trzy tomiki poezji oraz kilka książek dla dzieci i młodzieży, wierszem i prozą.

e-mail: abaluch@op.pl 